\title{
Optimal integrated management of groundwater resources and irrigated agriculture in arid coastal regions
}

\author{
J. GRUNDMANN, N. SCHÜTZE \& V. HECK \\ Technische Universität Dresden, Institute of Hydrology and Meteorology, Germany \\ jens.grundmann@,tu-dresden.de
}

\begin{abstract}
Groundwater systems in arid coastal regions are particularly at risk due to limited potential for groundwater replenishment and increasing water demand, caused by a continuously growing population. For ensuring a sustainable management of those regions, we developed a new simulation-based integrated water management system. The management system unites process modelling with artificial intelligence tools and evolutionary optimisation techniques for managing both water quality and water quantity of a strongly coupled groundwater-agriculture system. Due to the large number of decision variables, a decomposition approach is applied to separate the original large optimisation problem into smaller, independent optimisation problems which finally allow for faster and more reliable solutions. It consists of an analytical inner optimisation loop to achieve a most profitable agricultural production for a given amount of water and an outer simulation-based optimisation loop to find the optimal groundwater abstraction pattern. Thereby, the behaviour of farms is described by crop-water-production functions and the aquifer response, including the seawater interface, is simulated by an artificial neural network. The methodology is applied exemplarily for the south Batinah region/Oman, which is affected by saltwater intrusion into a coastal aquifer system due to excessive groundwater withdrawal for irrigated agriculture. Due to contradicting objectives like profit-oriented agriculture $v s$ aquifer sustainability, a multi-objective optimisation is performed which can provide sustainable solutions for water and agricultural management over long-term periods at farm and regional scales in respect of water resources, environment, and socio-economic development.
\end{abstract}

Key words groundwater; saltwater intrusion; irrigated agriculture; integrated water resources management; simulationoptimisation; decomposition; Oman

\section{INTRODUCTION}

The preservation of groundwater resources is a growing concern worldwide and the interdependent relationship between the agricultural industry and their management strategies has a large effect on future groundwater quality. Arid coastal regions are particularly vulnerable to reduced groundwater quality due to continuously growing populations with concomitant demands for irrigated agriculture. Coastal aquifers are often associated with water quality problems due to sinking groundwater levels. Excessive groundwater abstraction from irrigated agriculture has been shown to lead to marine saltwater intrusions worldwide, e.g. at the coasts of Mexico (Cardona et al. 2004), Australia (Narayan et al. 2007), Oman (Kacimov et al. 2009), and along the Mediterranean Sea. The resulting saline waters cause destruction to valuable agricultural resources - the economic basis for farmers.

Up to now, management problems are generally tackled in three ways: (1) by using simplistic models (e.g. linear programming) to solve management problems via common optimisation methods, or (2) by replacing optimisation with several alternative "what if scenarios" and then selecting the best alternatives that reach certain objective criteria from subjectively generated small samples (Harou et al. 2009). While the second approach results in suboptimal solutions, the first approach leads to an inadequate process description. Current management models do not provide realistic outcomes because they do not reliably portray nonlinear, interdependent phenomena of the complex hydrological system and their interdependency in a changing environment. Thus, uncertainties associated with future climate and global developments on the sustainable management of coupled groundwater-agriculture systems can be problematic. Therefore, a third approach (3), which is referred to as simulation-optimisation, was introduced by Gosavi (2003) who suggested a combined use of numerical mechanistic models and (black-box) optimisation methods. Unfortunately, the optimisation of complex water resources systems often becomes computationally intractable when solving simulation-optimisation problems with large numbers of design variables and/or objectives (Loucks and van Beek 2005).

To overcome these limitations classical simulation-optimisation strategies have been extended by two improvements (Grundmann et al. 2013): (1) customized tuned simulation-optimisation 
based on surrogate models (these are models which describe the behaviour of process models using only the most relevant features), and (2) the decomposition of complex optimisation problems. Surrogate models have been recently successfully applied for the management of coastal aquifer systems. Mostly, artificial neural networks (ANN) (Rao et al. 2004, Dhar and Datta 2009) or piecewise linear transformations (Rejani et al. 2009) are used in these studies to train the behaviour of groundwater flow models. Afterwards, these surrogate models are applied to solve mono-criteria (Rao et al. 2004) and multi-criteria optimisation problems (Dhar and Datta 2009).

Within this paper we present enhancements of a simulation-based integrated water management system for sustainable arid zone water management of interacting groundwater-agriculture hydrosystems developed by Grundmann et al. (2012, 2013). Despite rigorous surrogate model application, the solution of the general management problem is still computationally expensive, due to the large number of decision variables, if abstraction schemes, cropping patterns, and cultivated acreages are optimised simultaneously for multiple years. Therefore, a decomposition approach is applied and presented to separate the original large optimisation problem into smaller, independent optimisation problems which finally allow for faster and more reliable solutions. It consists of an analytical inner optimisation loop to achieve a most profitable agricultural production for a given amount of water and an outer simulation-based optimisation loop to find optimal groundwater abstraction patterns. The methodology is applied exemplarily for the south Batinah coastal region in Oman, which is affected by saltwater intrusion into a coastal aquifer system due to excessive groundwater withdrawal for irrigated agriculture. Due to contradicting objectives like profit-oriented agriculture $v s$ aquifer sustainability, a multi-objective optimisation is performed which can provide sustainable solutions for water and agricultural management over long-term periods at farm and regional scale.

\section{METHODOLOGY}

The enhanced simulation-based integrated water management system, illustrated in Fig. 1, consists of: (a) a procedure for deriving a groundwater surrogate model which calculates the aquifer response, (b) a procedure for deriving an agricultural surrogate model which simulates the behaviour of farms, and (c) an optimisation framework for linking both surrogates within a two-step optimisation procedure.

\section{The procedure for deriving the groundwater surrogate model}

The aquifer behaviour, including the seawater interface, is modelled by an ANN, namely by a multilayer perceptron net (Nabney 2002). It was trained using a scenario database containing the responses of the numerical density-dependent groundwater flow model OpenGeoSys (Kolditz et al. 2012) for all realistically feasible abstraction scenarios (Fig. 1(a)). The derived surrogate model, which is referred to as ANN-OGS, is used in the simulation-based management model for optimising the groundwater abstraction rates according to a selected objective function.

\section{The procedure for deriving the agricultural surrogate model}

For simulating the behaviour of highly productive agricultural farms, a database of crop-waterproduction functions (CWPF) is generated (see Fig. 1(b)). It describes the relationship between the applied amount of water and the produced yield for a given combination of crop/soil/climate under the assumption of optimal water application. For constructing stochastic CWPFs the OCCASION methodology (Optimal Climate Change Adaption Strategies in Irrigation by Schütze and Schmitz 2010) is used which incorporates the soil-vegetation-atmosphere transfer (SVAT) model APSIM (Keating et al. 2003), adapted to the regional climate conditions, together with the GET-OPTIS evolutionary optimisation algorithm for optimal irrigation scheduling and control (Schütze et al. 2012a). Considering salinity stress, the OCCASION-framework is extended by a second dimension, namely the salinity of the irrigation water using the salinity tolerance index (Steppuhn et al. 2005). Combining this index with a selected quantile of the SCWPF (e.g. the CWPF with 90\% reliability), 
the resulting 2D-CWPF ${ }^{0.9}$ additionally considers the water quality and allows for an appropriate choice of the crop patterns regarding their salinity tolerance.

\section{The optimisation framework}

The optimisation framework, illustrated in Fig. 1(c), connects the groundwater and agricultural simulation module and aims for managing both water quality and quantity according to the formulated objective function (equation (1)). The objective function $O F$ is of multi-objective type and considers the sustainability of the groundwater management - using a Sustainability Index SI, which evaluates the change of the aquifer state between the end and the initial state of the simulation period - and the agricultural Profit of farmers. Both objectives are contradicting. If the farmers want to get a high profit, they tend to pump as much water as possible. But this worsens the aquifer's situation due to a declining water table and an enforced saltwater intrusion.

In order to reduce the number of iterations and overall computation time, the originally large optimisation problem (Grundmann et al. 2012) is decomposed into an inner and an outer optimisation loop. The inner optimisation solves the agricultural profit optimisation problem, while the outer optimisation solves the overall groundwater management problem. In the outer optimisation, the objective function (equation (1)) is optimised for the extraction rates $Q_{i}$ (or water demands) over a certain simulation period $T_{n}$ with $i=1 \ldots n$ cultivation periods by the CMA-ES global evolutionary optimisation technique (Hansen et al.1996). From the extraction rates $Q_{i}$, the salinity $S\left(t_{i}\right)$ and water table heights $h\left(t_{i}\right)$ are derived by the ANN-OGS. Fixed and variable costs for pumping $C P\left(t_{i}\right)$ are also determined. For each cultivation period $i$, an inner optimisation loop is performed which aims to maximize the agricultural Profit by estimating the optimal crop pattern $A_{i}$ and cultivated acreage $L_{i}$ for the given amount of irrigation water $Q_{i}$ and irrigation water salinity $S\left(t_{i}\right)$. By means of the 2D-CWPF database, crop yields $Y_{j}$, revenues $P_{j} * Y_{j}$, as well as the irrigation costs $C I\left(t_{i}\right)$, resulting from the irrigation schedule, are estimated for the cultivated crops $j=1 \ldots m$, which together with the pumping costs $C P\left(t_{i}\right)$ forms the agricultural Profit optimisation problem. Due to the fact that CWPF's can be described by analytical functions (e.g. piecewise spline interpolations) the Profit optimisation problem can be solved analytically. This operates very fast and additionally allows for incorporating several farms within the inner optimisation loop. Finally, and in accordance to equation (1), SI and cumulated Profit are evaluated at the end of the simulation period considering varying weights $w$ between the two contradicting objectives.

$$
\max (O F)=w_{1} \sum_{i=1}^{n} \operatorname{Profit}\left(Q_{i}\right)+w_{2} S I(Q) ; \quad w_{1}+w_{2}=1
$$

\section{TEST SITE: THE WADI MA'AWIL CATCHMENT}

An exemplary application of the proposed management system illustrates the performance of the optimisation framework. We set up the application according to the characteristics of the wadi Ma'awil catchment located in the Batinah plain of the northeast coast of the Sultanate of Oman. Long-time overpumping of the coastal aquifer for irrigated agriculture has led to an inversion of the groundwater's natural flow direction resulting in marine saltwater intrusion and finally to a continuously increasing number of abandoned farms.

To demonstrate the optimisation framework functionality, a 2D vertical slice of the coastal aquifer is applied to model the groundwater flow inclusive saline transport. The test site's hydrogeology is characterised by a complex heterogeneous structure of alluvial, aeolian, and marine deposits, consisting of locally cemented gravels, differently sized sand, silt, loam and clay (Walther et al. 2012). Using a groundwater flow model based on OpenGeoSys, a density-dependent transient transport model for simulating the aquifer response to different extraction scenarios is constructed. Source terms within the model domain are applied to represent the extraction behaviour of the farmers with constant extraction rates during a cultivation period. The outlined model setup is used to generate a database containing the responses of the numerical density-dependent groundwater flow model for all realistically feasible abstraction scenarios. 
(a)

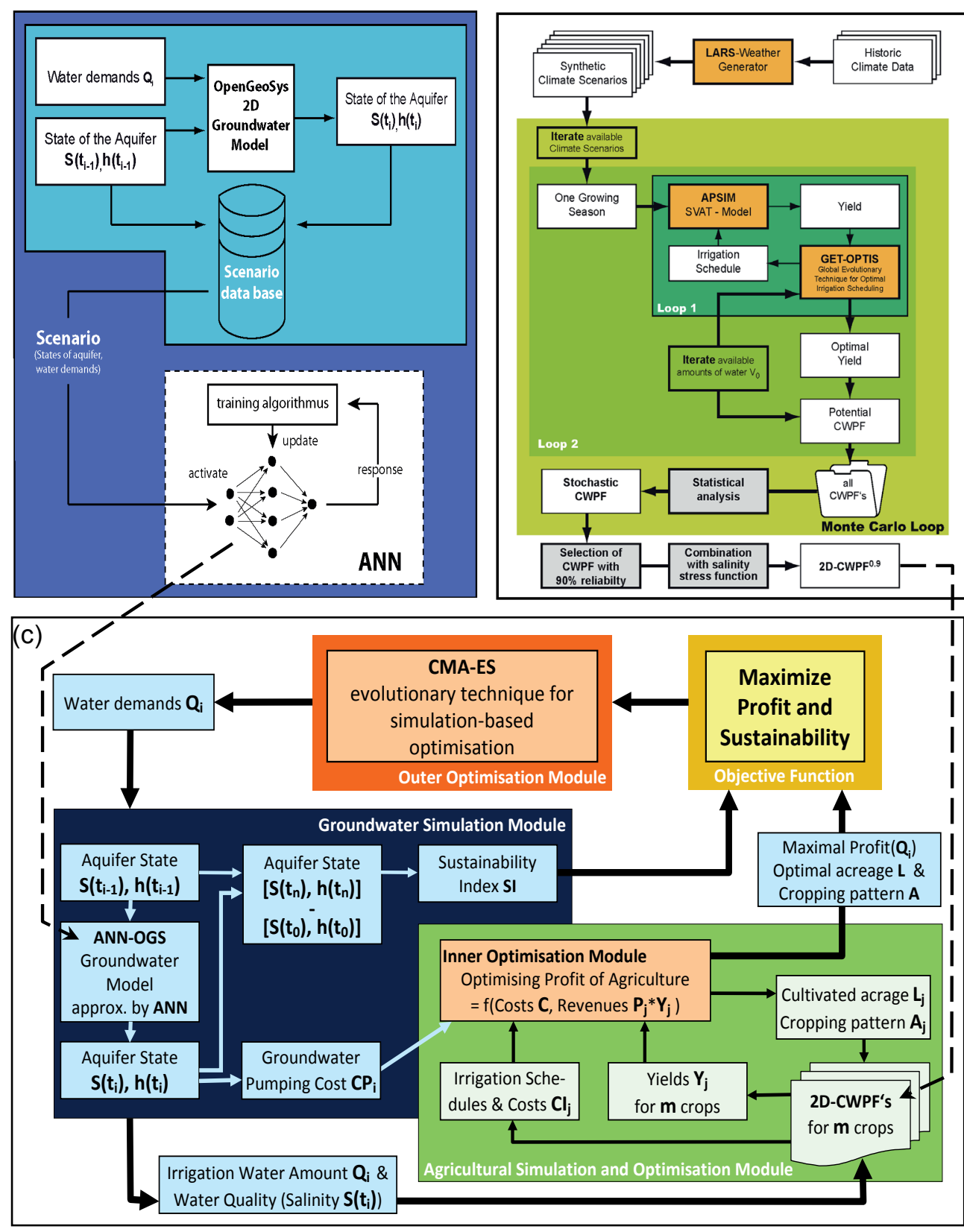

Fig. 1 Simulation-based integrated water management system consisting of: (a) the procedure of the set up of the surrogate model for describing the aquifer behaviour (ANN-OGS) (b) the estimation procedure for the 2D-crop-water-production function (2D-CWPF), and (c) the optimisation framework, which links the derived surrogate models.

These scenarios provide the basis for the training of the ANN-OGS surrogate model, which operates approximately 1000 times faster than the physically-based OpenGeoSys model (see Fig. 1(a) and Grundmann et al. 2012).

A long-term evaluation of the environmental and economic development of a sequence of hypothetical farms (located at different distances from the sea) under different management strategies is subsequently investigated. For the sake of simplicity, we assume the cultivation of two different crops: maize, a salt sensitive cash crop, and sorghum, a lower priced but more salt resistant crop, growing in two seasons per year. Assuming a yield reliability of $90 \%$, the resulting 2D$\mathrm{CWPF}^{0.9}$ indicates that sorghum achieves a higher yield for a given amount of water and has a higher 
salt tolerance than maize. However, the price per tonne for maize is higher than for sorghum, which offers a higher profit, if the water quality is good (for more details see Grundmann et al. 2012 and Schütze et al. 2012b). In addition to the surrogate models (ANN-OGS and the 2D-CWPF ${ }^{0.9}$ 's), fixed and variable costs for installation and operation of pumping and irrigation equipment are incorporated in the optimisation framework. A multi-objective optimisation run was performed to maximise the long-term profit together with the aquifer sustainability over the next 60 years. Decision variables are the cultivated acreage, the cropping pattern and the irrigation water demands for each cultivation period.

\section{RESULTS}

Selected results of the simulation-based integrated water management system for a multi-objective scenario, which compromise agricultural profit and aquifer sustainability at a specific farm location, are shown in Fig. 2. Due to increasing irrigation water salinity (Fig. 2(b)) the cropping pattern changes from maize to the more salt tolerant crop, sorghum (Fig. 2(c)). A further increase of the irrigation water salinity causes a reduction of the agricultural profit per year (Fig. 2(a)).
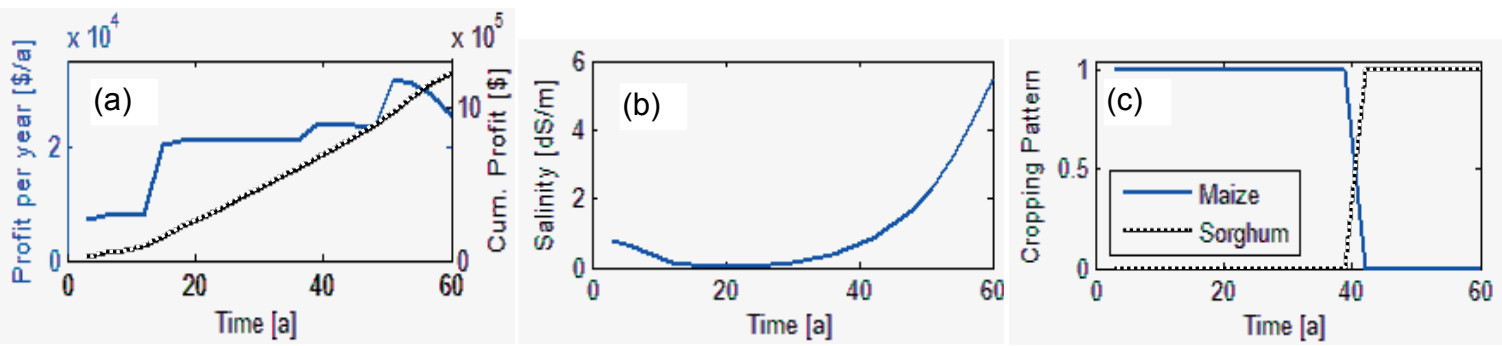

Fig. 2 Results of a multi-objective optimisation run illustrated by the profit (a), the salinity (b), and the cropping pattern (c) for a specific farm location.
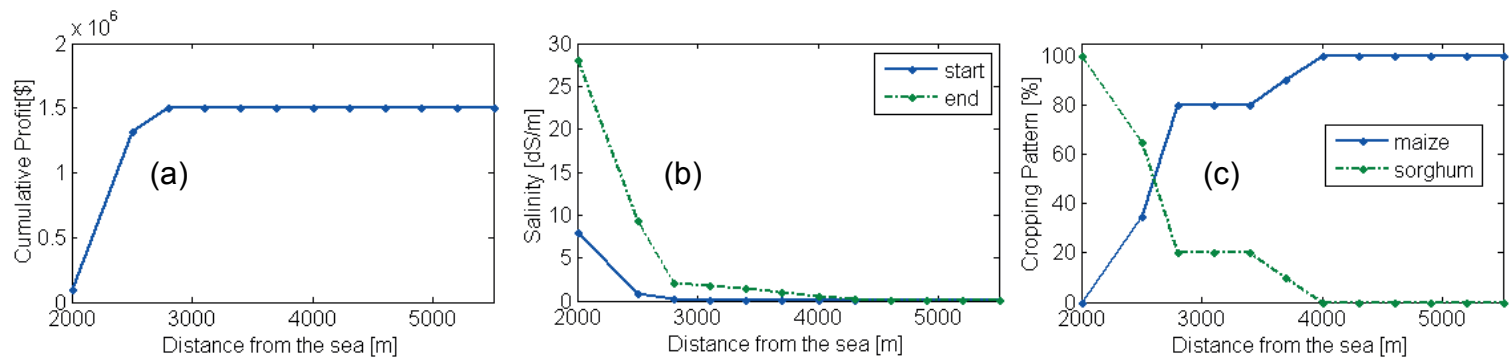

Fig. 3 Results of a regional optimisation for a profit-oriented optimisation run illustrated by the profit (a), the salinity (b), and the cropping pattern (c) as dependent on the distance from the sea.

Results of a regional optimisation for a profit-oriented scenario of 60 years are displayed in Fig. 3. Saltwater intrudes more inland with increasing time (Fig. 3(b)) and induces a regional specific optimal cropping pattern (Fig. 3(c)) for which maize is growing more inland and sorghum next to the sea. Farms located next to the sea show only a very small profit (Fig. 3(a)) compared to farms located more inland.

\section{CONCLUSION AND OUTLOOK}

The enhanced version of the presented simulation-based integrated water management system allows for the management of both water quality and quantity of a coupled dynamic groundwateragriculture system. The applied decomposition of the optimisation problem reduces the computational complexity by $85 \%$. A regional expansion of the optimisation is now possible, which allows for an optimisation of the regional cropping pattern and groundwater abstraction schemes. Thereby, the modelling of density-driven groundwater flow is mandatory for calculating crop yield damages due to aquifer overpumping and irrigation with saline water. The exemplary application, 
dealing with a typical management problem in coastal arid regions, shows that farm operation focusing exclusively on profit maximization leads sooner or later to further progress of the saltwater front. Therefore, the sustainability must be considered as a second optimisation objective to provide sustainable solutions, both in an environmental and social sense. Along these lines, the presented prototype forms the basis for the development of a large-scale management and planning system focusing on a sustainable arid zone water resources management. Further efforts are necessary to incorporate 3D density-driven groundwater flow modelling and appropriate surrogate model development, as well as the implementation of further crops and higher numbers of cultivation periods in order to perform a real case study in a pilot region.

Acknowledgement The manuscript was prepared within the research project IWAS funded by the German Federal Ministry of Education and Research (BMBF) under grant no. 02WM1166.

\section{REFERENCES}

Cardona, A., et al. (2004) Salinization in coastal aquifers of arid zones: An example from Santo Domingo, Baja California Sur, Mexico. Environmental Geology 45(3), 350-366.

Dhar, A. and Datta, B. (2009) Saltwater Intrusion Management of Coastal Aquifers. I: Linked Simulation-Optimization. Journal of Hydrologic Engineering 14(12), 1263-1272.

Gosavi, A. (2003) Simulation-Based Optimization: Parametric Optimization Techniques and Reinforcement Learning. Boston: Kluwer Academics Publishers.

Grundmann, J., et al. (2012) Towards an integrated arid zone water management using simulation based optimisation. Environmental Earth Sciences 65(5), 1381-1394.

Grundmann, J., Schütze, N. and Lennartz, F. (2013) Sustainable management of a coupled groundwater-agriculture hydrosystem using multi-criteria simulation based optimisation. Water Science \& Technology 67(3), 689-698.

Hansen, N. and Ostermeier, A. (1996) Adapting Arbitrary Normal Mutation Distributions in Evolution Strategies: The Covariance Matrix Adaption. Proceedings IEEE International Conference on Evolutionary Computation (ICEC '96), 312-317.

Harou, J. J., et al. (2009) Hydro-economic models: Concepts, design, applications, and future prospects. Journal of Hydrology $375(3-4), 627-643$

Kacimov, A., et al. (2009) Control of sea-water intrusion by salt-water pumping: coast of Oman. Hydrogeology Journal 17, 541558 .

Keating, B., et al. (2003) An overview of APSIM, a model designed for farming systems simulation. European Journal of Agronomy 18(3-4), 267-288.

Kolditz O, et al. (2012) OpenGeoSys: an open-source initiative for numerical simulation of thermohydro-mechanical/chemical (THM/C) processes in porous media. Environmental Earth Sciences 67(2), 589-599.

Loucks, D. P. and van Beek, E. (2005) Water resources systems planning and management: an introduction to methods, models and applications. Paris: UNESCO.

Nabney, I. (2002) Netlab. Algorithms for Pattern Recognition. Springer, London.

Narayan, K. A., Schleeberger, C. and Bristow, K. L. (2007) Modelling seawater intrusion in the Burdekin Delta Irrigation Area, North Queensland, Australia. Agricultural Water Management 89(3), 217-228.

Rao, S., et al. (2004) Planning groundwater development in coastal aquifers. Hydrological Sciences Journal 49(1), 155-170.

Rejani, R., Jha, M. K. and Panda, S. N. (2009) Simulation-Optimization Modelling for Sustainable Groundwater Management in a Coastal Basin of Orissa, India. Water Resources Management 23(2), 235-263.

Schütze, N., de Paly, M. and Shamir, U. (2012a). Novel simulation-based algorithms for optimal open-loop and closed-loop scheduling of deficit irrigation systems. Journal of Hydroinformatics 14 (1), 136-151.

Schütze, N., et al. (2012b) Optimal planning and operation of irrigation systems under water resource constraints in Oman considering climatic uncertainty. Environmental Earth Sciences 65(5), 1511-1521.

Schütze, N. and Schmitz, G. H. (2010) OCCASION: A new Planning Tool for Optimal Climate Change Adaption Strategies in Irrigation. Journal of Irrigation and Drainage Engineering 136(12), 836-846.

Steppuhn, H., van Genuchten, M. and Grieve, C. (2005) Root-zone salinity: II. Indices for tolerance in agricultural crops. Crop Science 45(1), 221-232.

Walther, M., et al. (2012). Saltwater intrusion modeling: verification and application to an agricultural coastal arid region in Oman. Journal of Computational and Applied Mathematics 236(18), 4798-4809. 